\title{
Fossil Finds Around Ancient Troy
}

\author{
Reyhan Korpe \\ Canakkale Onsekiz Mart University \\ Faculty of Arts and Sciences, Department of History \\ Terzioglu Campus \\ 17100 Canakkale, Turkey \\ E-mail: rkorpe@comu.edu.tr
}

\begin{abstract}
Greek myths mention the existence of a monster (ketos) arount the city of Troy. This monster was killed by Heracles at cape Agammia (now Kucuk Besire Burun). There is a scene on a Greek vase dated to the sixth century, which depicts the heroic deed of Heracles at Agammia. The head of the monster is unmistakably a large animal fossil skull. In our survey project around Troy, we found fossil beds in in Beşige Burun, which most likey is the source of Greek myths concerning the Monster of Troy.
\end{abstract}

Keywords: Troy, Fossill, Agammia, Kucuk Besige, Kumburun

DOI: $10.7176 / J S T R / 5-2-25$

\section{Troia Civarındaki Fosil Buluntular}

\begin{abstract}
Özet
Antik mitolojide Troia civarında birçok canavarın varlığından söz edilir. Ketos diye adlandırılan bir canavarın Herakles tarafindan Agammia burnunda öldürüldüğü söylenir. M.Ö. 6. yüzyıla ait bu mitolojik olayı anlatın vazo resminde bu canavarın başı belirgin bir şekilde fosil kafası şeklinde betimlenmiştir. Troia'nın hemen batısında bulunan Agammia burnu günümüzde Küçük Beşige burnu olarak bilinir. Antik çağda bölgede yaşayan insanların Küçük Beşige burnunda deniz kıyısında bulunan fosil kalıntıları görerek böyle bir mitolojiyi yaratmış olmalıdırlar.
\end{abstract}

Anahtar Kelimeler: Troia, Fosil, Agammia, Küçük Beşige, Kumburun

\section{Giriş}

Troia antik kenti ve çevresinde yaklaşık iki yüzyıldan bu yana yapılan incelemeler bölgenin sadece tarihsel ve arkeolojik geçmişine değil çok daha eski dönemlerine ait kalıntıları da gün yüzüne çıkarmıştır. Bölgedeki en erken insan yerleşimlerinden binlerce yıl önce yaşamış olan canlılara ait fosil kalıntıları Ege Denizi ve Çanakkale Boğazı kıyıları boyunca görülebilmektedir. Bölgede bulunan fosil kalıntıları ile ilgili 19. yüzyıldan bu yana araştırmalar yapılmakta olup, kalıntıların Miosen (belki Alt Miosen) dönemine ait oldukları düşünülmektedir. Fakat Troia civarında görülen bu fosil kalıntılarının antik çağlardan beri bölgede yaşayan insanlar tarafından görüldüğü ve bunların bir şekilde kendi mitolojilerine de aktarıldığ anlaşılmaktadır. Bu makalede Troia civarında bulunan fosil kalıntıları ile bu kalıntılardan özellikle 1998 yılında Kumburun yakınlarında tespit edilen fosillerin Troia mitolojisinde nasıl yansıdığı ele alınmıştır.

\section{Troia Civarındaki Fosil Araştırmaları}

Troia civarındaki fosillerden modern çağlarda ilk defa bahseden İngiliz coğrafyacı ve haritacı Spratt olmuştur. Spratt, Forchhammer ile birlikte Troia civarının jeolojisi üzerine çalışmalar yaparken bölgenin hemen kuzeyinde, Erenköy civarında omurgalı hayvan fosilleri bulduğunu bildirir (Forchhammer ve Spratt, 1850). Fakat bu fosiller ile ilgili ilk ciddi çalışmaları gerçekleştiren Frank Calvert'tir (Allen, 1999). Troas’ta ilk arkeolojik çalışmaları başlatan Calvert, aynı zamanda bölgenin jeolojik yapısıyla da yakından ilgilenmiştir. Çanakkale'de İngiliz-Amerikan konsolosu olan Calvert'in bu arkeolojik araştırmalarının yanı sıra aynı zamanda bölgenin madenleriyle de ticari olarak ilgileniyordu. Bu nedenle Çanakkale'nin pek çok yerinde sondajlar yapmıştır. Calvert'in, Spratt'ın sözünü ettiği fosilleri bulduğu, konuyla ilgilenen amatör jeologlar tarafindan kısa sürede duyulmuştur. 1872 yılında, İstanbul'da Robert Koleji hocalarından 
G. Washburn İstanbul Boğazında yaptığı jeolojik araştırmalar sırasında Calvert'inMiosen döneme ait birtakım kalıntılar bulduğunu öğrenmiş ve bunları görmek için Çanakkale'ye gelerek Calvert'i ziyaret etmiştir. Washburn'un ziyaretinde Calvert, kendisine fosillerle birlikte bunların çıktığ 1 yeri de göstermiştir (Washburn, 1909). Washburn bu ziyaretinden üç yıl sonra TheCanadianNaturalist adlı jeoloji dergisinde "Calvert, Dardanel'in Miosen tabakalarındaki kalıntıların insana ait olduğunu iddia ediyor" başlığı ile ayrıntılı bir makale kaleme almıştır. Washburn bu makalesinde Calvert'in kendisine göstermiş olduğu buluntular hakkında daha ayrıntılı bilgi vermektedir. Washburn, incelediği kalıntıların Miosen döneme ait Mastodon ya da Dinotherium fosil kemikleri ve dişleri olduğunu söylemektedir (Washburn, 1875).

Calvert, Hellespontos kıyısından topladığı buluntuları Viyana'da M. Neumayr'e haber verince, Neumayer 1874 'te bunları görmek için Troas'a gelir. Birkaç yıl sonra da ikilinin çalışmaları buluntu yerinin ayrıntılı çizimleri ile birlikte 1880 yllında Denkschriften der KaiserlichenAkademie der Wissenschaften'de“DieJungenAblagerungen am Hellespont” başlığıyla makalesi yayınlamıştır (Calvert ve Neumayr, 1880). Bu makalede Neumayer, Calvert'in bulduğu tüm örnekleri tek tek inceleyerek buluntuları gruplamıştır. Bazı örneklere de bölge adını yansıtır isimler vermiştir. Bu çalışma Troas’ta şimdiye kadar yapılmış en eski ve en kapsamlı çalışmadır. Gönderilen buluntular içinde çoğunlukla deniz kabukluları bulunmaktadır. Hellespontos girişinde Erenköy’ün batısında denize dik inen kesitler içinde bulunan kara canlılarına ait fosillerin ise Mastodonangustidens, Mastodonlongirotris, Hippotheriumgracile ve Camelopardalisattica, Sus erymanthius, TragocerosamaltheusvePalaeoreas oldukları anlaşılmıştır. Calvert ve Neumayr'ın üzerinde çalıştığı fosiller arasında sadece İntepe civarından değil, boğazın içlerinden Nara burnundan, Lapseki'ye kadarki kıyı kesiminden de toplanan örnekler vardır. Çanakkale arkeoloji müzesi koleksiyonunda bulunan ve Calvert koleksiyonuna ait olduğu bildirilen bir grup fosil örneği olasılıkla bu toplanan parçalardır.

Schliemann 1870-1880 yıllarında Troia'da yaptığı kazılarda M.Ö. 13. yüzyıla tarihlenen tabakalar arasında bazı ilginç taşlaşmış kemik parçaları bulmuştur. Ne olduğunu öğrenmek için British Museum'a gönderilen buluntuların günümüzden sekiz milyon öncesine ait Miosen dönemde yaşamış memelilere ait oldukları öğrenilmiştir (Schliemann, 1880). Schliemann'ın keşfi antik Troialıların çevrede bulunan birtakım fosilleşmiş kemikleri topladığını göstermiştir. Her ne kadar Schliemann fosillerin M.Ö. 13. yüzyıllara ait tabakalardan çıktığını bildiriyorsa da, bu fosillerin Philostratos'un (Heroica2.3) bahsettiği Hadrianus'unTroia'da gömdüğ̈̈ Aias'ın kemiklerin olma olasılığı da vardır. Fakat bu fosil buluntuları Troia kazılarında bulunan diğer göz kamaştırıcı buluntuların gölgesinde kalarak hiçbir zaman hak ettiği ilgiyi bulamamış ve zaman içerisinde önemini kaybetmiştir (Mayor, 2000).

19. yüzyılda Tchihatcheff ile başlayan çalışmalar ve özellikle son yıllarda Çanakkale'de yapılan jeolojik araştırmalar bölgenin fosil buluntular bakımından oldukça zengin olduğunu göstermiştir (Tchihatcheff, 1866-1869). Güneyde Babakale burnundan başlayan bir hat üzerinde, Bozcaada da dahil olmak üzere yarımadanın batı kıyıları ve Çanakkale boğazında yapılan araştırmalarda çok sayıda fosil yatağı bulunmuştur. F. Ozansoy, Çanakkale boğazı bölgesinde Anadolu yakasında, Çanakkale-Bayrak tepe ve Lapseki-Eski Subaşı köyü yapmış olduğu uzun süreli araştırmalar sonucunda Hipparion'lubiyozonlar bulmuştur (Ozansoy, 1969). Ozansoy ayrıca daha önce Calvert- Neumayer tarafından araştırılmış olan İntepe'nin boğaza bakan kesitlerinde, daha ayrıntılı incelemelerde bulunmuş ve buradaki tabakaların tarihlemelerini yaparak hangi tabaka içinde hangi fosillerin bulunduğunu tespit etmiştir (Ozansoy, 1957). Atın atalarından olan Hipparion türüne ait fosil kalıntıları Gülpınar civarında da çıkmıştır. Gülpınar yakınlarında deniz kıyısındaki yamaçlardan toplanan hipparion fosillerinin yanı sıra ,bölgedeki Neosen kayalar içinden Hyaena sp.,Ictitberiumhipparionum, Metailurusparvulus, Felisattica, Hipparioncf. matthewi, Hipparion sp.,Ancylotheriumpentelicum gibi kara memelilerinin fosilleri de bulunmuştur (Forsten ve Kaya 1995).

Çanakkale'nin 10 km güneybatısında bulunan Bayraktepe'de (Radartepe) 1960'lı yılların sonundan itibaren yapılan çalışmalarda özellikle Miyosen döneme ait çok sayıda denizsel ve karasal omurgalı fosili kalıntısı açığa çıkarılmıştır (Ozansoy, 1964; Ozansoy, 1973). Bu bölgedeki özellikle Miosen sonu ve erken Pliosen tabakalar içindeki memeli fosillerinin Avrupa ve Asya arasındaki faunikskalayı daha da kuvvetlendirdiği ileri sürülmektedir (Tekkaya, 1973). Bayraktepe'de bu memeli fosillerine ek olarak günümüzde yaşayan gergedanların atası olan Rhinocerotidae familyasına ait bazı diş ve kemik fosilleri ile gene günümüzdeki fillerin atası olan hortumlular familyasından Steneofiberjaegeri'e ait bazı diş ve çene kemiği fosilleri ele geçmiştir (Ünay, 1976; Kaya, 1992).

Bölgenin jeolojisi hakkında ilk incelemelerde bulunan Spratt, Tchihatcheff, Calvert-Neumayer, Philippson, Erguvanlı, bütün Çanakkale bölgesinde, Eosen döneminden sonra denizin çekildiğini ve muhtemelen Miosen (belki Alt Miosen) döneminde, bölgede göl rejimi başladığını bildirirler (Kalafatçıŏlu, 1963 ). Miosenin sonunda göl rejimi bozulmuş ve Alt Pliosende yeni bir sedimantasyon 
baseni tekrar teşekkül etmiştir. Bölgede bulunan fosil örnekleri bu dönemlerde yaşamış olan memelilere aittir.

\section{Kumburun Fosilleri}

19. yüzyıldan bu yana bölgede yapılan jeolojik araştırmalar Ege Denizi ve Çanakkale Boğazı kıyılarında oldukça zengin fosil yataklarının bulunduğunu göstermektedir. Fakat yakın zamanda Troia çevresinin jeoarkeolojisi ve Homeros Troiası'nın limanları ile ilgili çalışmalar yapan İlhan Kayan ve ekibinin yayınlarında Ege denizi ve Çanakkale Boğazı girişinde bu tür bulgulara ait herhangi bir bilgi bulunmamaktadır. (Kraft, Kayan ve Erol, 1980; Kayan, 1991; Kayan, 1995; Kayan, 1996; Kayan, 1997; Kayan, 2002; Kraft, Rapp, Kayan ve Luce, 2003; Kayan, 2005).

Muhtemelen 1998 yılında deniz kıyısında meydana gelen bir toprak kaymasıyla Çanakkale'nin Ezine ilçesi, Kumburun köyünün yaklaşık $3.5 \mathrm{~km}$. batısında, Küçük Beşige burnunda deniz kıyısındaki kayalarda kemik kalıntıları açığa çıkmıştır. Çanakkale Müzesi uzmanlarının yaptı̆̆ı ilk inceleme sonrasında bunların fosil olduğu anlaşılmıştır. Daha sonra İstanbul Teknik Üniversitesinden Mehmet Sakınç'ın incelemeleri sonucunda fosilleşmiş kemik kalıntılarının yaklaşık 5-4 milyon yıl önce karasalgölsel koşulların egemen olduğu bir ortamda yaşamış omurgalı hayvanlar şubesinin, memeliler sınıfından birkaç hayvana ait olabileceği kanısına varmıştır (Görür ve arkadaşları, 1997). Sakınç incelemeleri ile ilgili yazmış olduğu tanıtım makalesinde buradaki fosillerin hangi canlılara ait olduğu hakkında kesin bilgi vermezken, sadece bu dönemde bu faunada yaşayan çeşitli türleri şu şekilde sıralar: Zürafalar/ Giraffidae, Sığır, Koyun, Antiloplar/ Bovidae, Sırtlanlar/ Hyaenidae, Gergedanlar/ Rhinoceratidae, FillerHortumlugiller/ Proboscidae, Etciller/ Carnivora, Suaygırlar1/ Hippopotamidae, Geyikler/ Cervidae, Kemirgenleri/ Rodentia, Atgilleri/Equidae, Domuzları/Suidae ve insanımsılar1/ Hominoide sayar (Sakınç ve Ülgen, 1998).

Fosillerin çıktığı yer, Beşige burnunun denize dik olarak inen yarların dibinde, hemen deniz kıyısında, 1 $2 \mathrm{~m}$. genişliğinde ve yaklaşık 10-12 m. uzunluğunda dar bir bant üzerindedir. Fosil kemikleri gruplar halinde olup, kemiklerin yönü fosilleşmenin in situ olmadığını gösterir. Sakınç bu durumu hayvanların öldükten sonra kemiklerinin akarsuların çökelme ortamına taşınmış olmasına bağlamaktadır (Sakınç ve Ülgen, 1998).

Küçük Beşige, Troia coğrafyasında, Troia’nın yaklaşık $10 \mathrm{~km}$. güney batısında, Büyük Beşige burnunun kuzeyinde, Ege denizine uzanan küçük bir burundur. İki Beşige burnu arasında bulunan Beşige koyunun Troia mitolojisinde önemli bir yeri vardır. Bu koy Troia savaşlarında Akaların karaya çıktığı ve kamplarını kurduğu yer olarak bilinir. Antik çağlarda Büyük Beşige burnu Akhilleion olarak bilinirken, Küçük Beşige ise "Agammia" olarak bilinmekteydi (Bruchner, 1923). Cramer ve Napier, Sigeion burnunda, şimdiki Yeni Şehir' in biraz güneyindeki diğer burunda olduğunu ve buradaki küçük yerleşimin Agamia kasabası olduğunu (Leake, 1824; Cramer, 1832; Napier, 1840), Clarke ve Leaf ise, Agammia'nın Beşik burnu ve koyu olduğunu söyler (Clarke, 1898; Leaf, 1923). Cook ise Agammia'nın bir yerleşim olmadığını, burasının deniz içinde çıkıntılı bir kayalık, topuk olduğunu bildirir (Cook, 1973).

Burun üzerinde ve civarında yaptığımız araştırmalarda yüzeyde dağınık halde bulduğumuz birkaç antik seramik dışında bir yerleşimi işaret eden kalıntılara rastlanmamıştır (Körpe 2010). Bu da Agammia'nın bir yerleşim yerinden çok buradaki burnun adı olduğunu göstermektedir. Antik çağın ünlü coğrafyacısı Strabon ise bölge hakkında bilgi verirken buradan Agameias burnu olarak bahseder. Strabon bunun dişında diğer antik kaynaklarların sözünü ettiği Troia canavarının buluntu yeri hakkında daha ayrıntılı bilgi vererek, canavarın Agameias burnu yakınlarından çıktığını söyler (Strabon, 13.1.30-32). Strabon dışında StephanosByzantios da, Herakles'in Troia prensesi Hesione'yiAgammia yakınında Poseidon'un gönderdiği deniz canavarından kurtardığını bildirmektedir (StephanosByzantios, V. $\alpha \gamma \alpha \mu \varepsilon \imath \alpha$ ).

Antik dönem mitolojisine konu olmuş olan bu olay bir Yunan vazosu üzerinde tasvir edilmiştir. M.Ö. 560540 yıllarına tarihlenen destekli krater üzerinde, kraterin kulpları arasındaki ana frizde yukarıda bahsedilen Hesione'nin Herakles tarafindan kurtarılmasını anlatan mitolojik olay anlatılmaktadır (Amyx 1988). Fakat vazo üzerindeki betimlemedeki "canavar" daha önceden bildiğimiz Yunan vazoları üzerindeki tasvirlerden oldukça farklıdır. Daha önce Herakles ile mücadele eden hiçbir mitolojik yaratığa benzemeyen, deniz ya da kara canlısı olduğu anlaşılmayan, vücudunda baş kısmı hariç gövdesinin diğer uzuvlarını göremediğimiz yaratık, sadece beyaz bir kurukafadan ibarettir. Bu beyaz kurukafanın çıktığı yer siyah renkli şekilsiz bir kütleden ibaret olup, bu kütlede de uzuv olabilecek herhangi bir detay görülmemektedir. Beyaz kafatası adeta bu siyah kütle üzerinde yapışmış gibidir. Kafatası bu siyah kütlesin bir parçası gibi gözükmekle birlikte ressam özellikle beyaz renkle bunu ayırmıştır. Vazo üzerindeki yaratık sadece kayalık zemin üzerinde beyaz bir kurukafadan ibarettir denilebilir. Ressam burada hayali bir canavardan ziyade oldukça realistlik bir şekilde bu kafatasını çizmeye çalışmıştır. Bildiğimiz hiçbir canavara benzemeyen bu yaratığın kökeni ise antik dönem mitolojik yaratıklarına değil, jeolojik 
dönemlerin gerçekten yaşamış canlılarına kadar uzanmaktadır. Sanatçı canavarın kafasını büyük bir fosil hayvan başı gibi göstermiştir (Mayor, 2000). Antik çağ mitolojisinde Troia canavarı olarak tanınan yaratığın aslında kayalardan çıkan bir fosil kalıntısı olduğu oldukça açıktır.

\section{Sonuc}

Çanakkale civarındaki ilk insan yerleşimleri günümüzden yedi bin yıl öncesine gitmektedir. Fakat bölge insanlar gelmeden önce de canlıların yaşamasına uygun bir yer olduğundan özellikle Miosen dönemde oldukça zengin bir faunaya sahipti. Bu döneme ait fosil kalıntılara günümüzde Çanakkale'nin Ege Denizi kıyıları ile Çanakkale Boğazı boyunca çeşitli arazi kesitlerinde rastlanmaktadır. Bu fosil kalıntılarının günümüzde olduğu gibi antik çağlarda da bölgede yaşayan insanlar tarafindan görülmüş oldukları hiç kuşkusuzdur.

1998 yilında Kumburun'da bulunan fosillerin aslında binlerce yıldır bölgede yaşayan insanlar tarafindan görüldüğü ve yakından inceledikleri anlaşılmaktadır. Fakat bu fosiller geçmişin gizemli canavarları olarak kendi yarattıkları mitolojiye dahil edilmiştir. Kumburun fosilleri antik mitolojinin nasıl oluştuğu ve mitolojideki doğaüstü yaratıkların kökeninin aslında benzer jeolojik ve doğa olaylarından kaynaklandığını gösteren önemli bir örnektir.

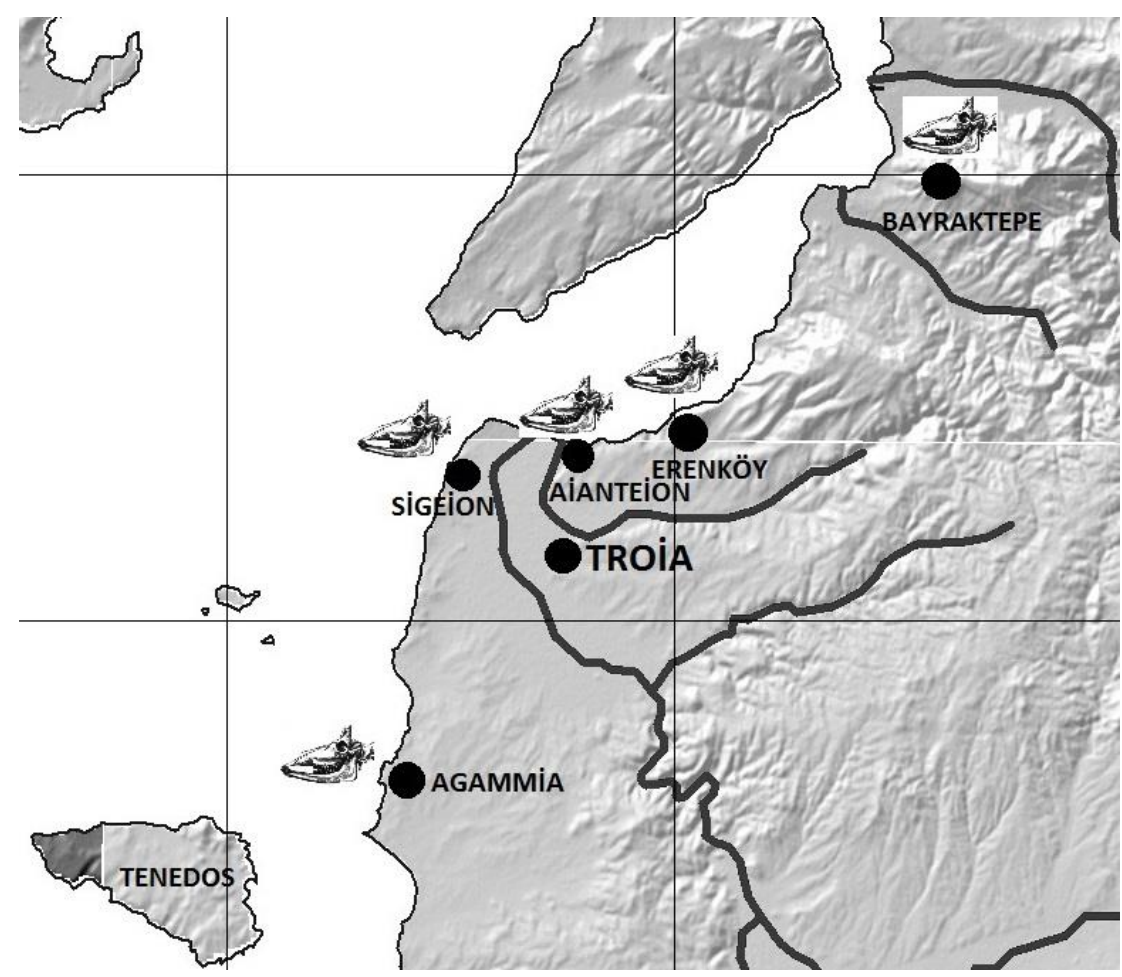

Figure 1: Troia Civarındaki Fosil Buluntular

\section{Kaynakça}

Allen, S. H (1994). "Finding the Walls of Troy: Frank Calvert, Excavator", AJA 99, 379-407.

Amyx, D. A (1988). Corinthianvase-painting of the Archaicperiod, Volume 2, University of California Press

Bruchner (1923), RE, “Agammia”, Bd1.

Calvert, Frank ve Neumayr, M (1880). "DieJungenAblagerungen am Hellespont", Denkschriften der KaiserlichenAkademie der Wissenschaften, Band. XXVI-XL 365- 414.

Clarke, J. Th (1898). Report on the Investigations at Assos, 1882, 1883, New York.

Cook, J. M (1973). The Troad, Oxford. 
Cramer, J. A (1832). A Geographiccal and HistoricalDescription of AsiaMinor, Oxford.

Forchhammer ve Spratt (1850). Ebene vonTroia, Frankfurt.

Forsten- Kaya, T (1995). "The hipparions (Mammalia, Equidae) from Gülpınar (Çanakkale, Turkey)” PaläontologischeZeitschrift 58, 491-501.

Görür, N., Çağatay, M. N., Sakınç, M., Sümengen, M., Şentürk, K., Yaltırak, C., Tchapalyga, A (1997). "Origin of the Sea of Marmara as deducedfromNeogenetoQuaternarypaleo-geographicevolution of itsframe”, Int. Geol. rev. 39, 342-352.

Kalafatçıŏglu, A (1963). "Ezine civarının ve Bozcaada'nın jeolojisi, kalker ve serpantinlerinin yaşı", MadenTetkik ve Arama Dergisi 60, 60-70.

Kaya, T (1992). "Bayraktepe'de (Çanakkale) Rhinocerotidae fosilleri”, Maden Tetkik ve Arama Dergisi114, 145-155.

Kayan, İ (1991). "Holocenegeomorphicevolution of the Beşik plain and changingenvironment of ancientman" Studia Trioca 1,79-92.

Kayan, İ (1995). "The Troia bay and supposedharboursites in the Bronze Age” Studia Trioca 5, 211235.

Kayan, I (1996). "Holocenestratigraphy of the LowerKaramenderes-Dümrekplain and archaeologicalmaterial in the alluvialsedimentsto the north of the Troiaridge", StudiaTroica 6, 239249.

Kayan, İ (1997). "Geomorphologicalevolution of the Çiplak valley and archaeologicalmaterial in the alluvialsedimentsto the south of the Lower City of Troia", StudiaTroica 7, 489-507.

Kayan, İ (2002). "Paleogeographicalreconstruction on the plainalong the western foot-slope of Troy" Mauerschau: FestschriftfürManfredKorfmann 3. 993-1004.

Kayan, İ (2005). “Karamenderes Deltasının (Çanakkale) Holosen Stratigrafisi ve TroiaJeoarkeolojisi Bakımından Değerlendirmesi”, Türkiye Kuvaterner Sempozyumu, TURQUA-V,2-5 Haziran 2005, $77-81$.

Körpe R (2010). “Küçük BeşigeAgammia Fosilleri ve Troia Mitolojisindeki Yansımaları”, KUBABA, $7-22$.

Kraft, J. C., Kayan, İ. ve Erol, O (1980). "Geomorphicreconstructions in the environs of ancientTroy", Science. American Association for the Advancement of Science. 209, No. 4458, 776-782.

Kraft, J. C., Rapp, G., Kayan,İ. ve Luce,J. V (2003). "Harborareas at ancientTroy: Sedimentology and geomorphologycomplementHomer's Iliad”, Geology 31, 163-166.

Leaf, W (1923). Strabo on The Troad, Cambridge.

Leake, W. M (1824). Journal of a Tour in AsiaMinor, London.

Mayor, A (2000a). The First FossilHuntersPaleontology in Greek and Roman Times, Oxford.

Mayor, A (2000b). “A Time of Giants and Monsters”,Archaeology, 53:2, 19.

Mayor, A (2000c). "The Monster of TroyVase: The EarliestArtisticRecord of a Vertebrate Fosil Discovery?", Oxford Journal of Archaeology19, 27-63.

Napier, N (1840). "Remarks on Ancient Troy and Modern Troad", The United Service Journal, London. 
Ozansoy, F (1957). "Definition OderErlauterungEinigerWichtigerBegriffeZurGranitfrage”, Bulletın of TheGeneral Directorate of MineralResearch and Exploration of Turkey 49, 29-48.

Ozansoy, F (1964). "Fauni-zon birimleri ışığında Çanakkale çevresi Neojen stratigrafisi ve Neojen paleocoğrafyasında bölgede tabii rejimler problemi, karasal-denizel-somatr ve karasal", $A \ddot{U D T C F}$, Antropoloji Dergisi 1,2, 32-55.

Ozansoy, F (1969). "Türkiye'nin ilk denizel fosil Memeli faunası ve Miosen-PliosenTetis-Paratetis münasebetleri hakkında", AÜDTCF, Antropoloji Dergisi 4, 121-164.

Ozansoy, F (1973). "Lescaracteristiques de NeogenedesDardanalles”, AÜDTCF, Antropoloji Dergisi $6,171-180$.

Sakınç, M. ve Ülgen, U. B (1998). “5 milyon yıl önce Çanakkale’de kimler yaşadı?”, Cumhuriyet Bilim Teknik 614, 18-19.

Schliemann, H (1880). İlios, London.

Tchihatcheff, P (1866-1869). De. AsieMinore, Paris.

Tekkaya, İ (1973). "Çanakkale güneydoğusundaki Bayraktepe Omurgalı faunası hakkında ön rapor”, Maden Tetkik ve Arama Dergisi 81, 191-195.

Ünay, E (1976). "The Remains of SteneofiberJaegeriKaup (Rodentia, Mammalia) Found in the Çanakkale Region", Bulletın of The General Directorate of Mineral Research and Exploration of Turkey 86, 95-100.

Washburn, G (1875). "Calvert'sSupposedRelics of Man in The Miocene of The Dardanelles", The CanadianNaturalist and QuarterlyJournal of Science 7, 155-157.

Washburn, G (1909). FiftyYears in Constantinople and Recoll, Boston and New York. 